\title{
Honoring Charles A. Ferguson
}

It took almost a month for Charles Ferguson and me to realize that we were living next door to each other during the Summer Linguistic Institute of 1964 at Indiana University. We had each come to Bloomington, with our respective families, in order to participate in the Seminar on Sociolinguistics that the Social Science Research Council was sponsoring at the Institute that summer. Ferguson was the chairman of the Seminar, primus inter pares, the participants all being faculty members selected from a wide variety of disciplines. That summer I also took my first linguistics course, attending Ferguson's "Introduction to Linguistics" offered through the Summer Linguistic Institute. Prior to that summer we had communicated only once in writing and once over the telephone (although I had read his diglossia article and "knew who he was"). In the summer of 1964 we became neighbors, colleagues, students (each acknowledging the other as teacher) and close friends, roles that we have enacted, either repeatedly or continuously, during the past two decades and more.

I start off in this personal vein because Ferguson is reacted to precisely in this vein by a legion of neighbors, colleagues, students-teachers and close friends all over the globe. While it is true that his scholarship is both impeccable and seminal, it is even truer, and even more to the point in capturing the spirit of what Ferguson means to all those who have been privileged to know both the man and his work, that no one has ever felt about him (as we have all felt about so many other great scholars) that because his scholarship was unblemished it was justifiable to overlook his blemishes as an individual. Anecdotes about Ferguson as a fine human being, concerned for the welfare not only of his friends but of humankind, and not only for the welfare of humankind but for flesh and blood individuals, streamed into the Editorial Group's office as soon as invitations were sent out inviting participation in this Festschrift. These anecdotes deal with acts of kindness and charity, hospitality and help. Taken together they provide testimony to a wonderful human being about whom it can be said without exaggeration that by honoring him we honor ourselves. The primary feeling toward Ferguson that we all share is not only one of admiration but of affection, the two together making for a very rare tribute.

However, it is ultimately Ferguson the scholar to whom this Festschrift is addressed. If Ferguson's status as an exemplary human being led to the rare phenomenon of busy scholars pleading with the 
Editorial Group to be permitted to participate in the Festschrift, then Ferguson's status as an exemplary, multifaceted scholar led to the fact that these volumes are, of necessity, subdivided into a large number of different substantive areas. Indeed, it is difficult to find rivals to Ferguson in connection with either scope of interest or depth of contribution. Accordingly, scholars from half a dozen different areas of specialization recognize Ferguson as a mentor and, indeed, as a force who unites them and who points out their relevance for each other and for the total language-related enterprise. Child language (as well as "baby talk") and Arabic, universals and sociolinguistics, phonology and applied linguistics, language of religion and sports announcer register, in Fergusons' hands and mind these all come together and enrich each other and pose questions to each other. Ferguson has not only contributed to all of these areas but he has impacted them, adding to their depth, widening them, interrelating them in his own work and introducing them to each other via his influence on the thought of countless students and colleagues.

Although this integrative role can be noted utilizing any one of the foregoing fields or topics as point of departure, it is particularly from the perspective of sociolinguistics that his magic touch becomes crystal clear. Ferguson has the rare capacity of seeing all language-related phenomena in societal perspective, even the deepest structure and the most universal aspects manifesting sociocontextual, sociofunctional and sociohistorical influences in his work. From the very genesis of modern sociolinguistic efforts in the late 50's, Ferguson has served as exemplar, umpire, godfather (even fairy godmother), gentle critic and proud defender of the field. Both intellectually and intuitively he recognized its potential for more realistic, more valid, more thoughtful and more provocative insights into language related behavior. His contributions to this fledgling field can hardly be exaggerated. His espousal of the field provided it with a man of distinction, with a "name" that opened doors, prompted support, suggested confidence and reassured doubting Thomases, from the very outset. That sociolinguistics could not only hold its own but advance and grow strong, doing so initially during the very period when the Chomskian revolution was orienting linguistics in a non-sociolinguistic direction, is in no small part due to Ferguson's quiet but very evident identification with it.

However, Ferguson's contribution to the sociolinguistic enterprise goes far beyond narrow sociolinguistics per se. He has always embraced sociology as well as linguistics, political science as well as anthropology, education as well as phonology, history as well as mor- 
phology, economics as well as syntax, in short: a complete multi-level, multi-method approach to language in society, in order to build the broader understanding which is the new discipline's ultimate quest. This, indeed, is the truest measure of a scholar: one who does not cut down a field to his own size, to his own areas of personal expertise or to his own methodological competencies, but, instead, recognizes, encourages and acquires the widest possible repertoire of methods and substantive emphases. Ferguson has elevated the sociolinguistic enterprise by infusing into it his own catholicity of interests, his own acceptance of diversity of methods, his own openness to intellectual stimulation regardless of disciplinary origin. He has provided the field with a receptivity for both data and theory, for both applied and academic emphases, which, hopefully, it will never "outgrow". Finally, the strong moral dimension that underlies all of Ferguson's life and work, his individual nature as well as his scholarly nurture, can only serve to guarantee that the broad-gauged sociolinguistic enterprise which he has helped launch will never be put to distructive, self-aggrandizing, inhumane and non-humanistic purposes. Our trust in the moral soundness of the field mirrors our trust in his own moral and ethical example to us all.

These volumes could not have been realized without the collaboration of scores of individuals and a cooperative publisher, united by a sense of admiration for a wonderful human being and a fine scholar. The Editorial Group (Mohamed Abdulaziz, Michael Clyne, Joshua A. Fishman, Bh. Krishnamurti and Andrée Taburet Keller) is grateful to them all, and particularly for their help and self-discipline in assuring the publication of these books in time for their presentation to Professor Ferguson on the occasion of the celebration of his 65th birthday. We pray that these volumes may provide the same stimulation to the further growth of the language-related disciplines and studies that Charles A. Ferguson himself has so admirably provided - and will yet continue to provide - for many, many years.

Joshua A. Fishman, Chairman Editorial Group 
